Article

\title{
News Media Performance Evaluated by National Audiences: How Media Environments and User Preferences Matter
}

\author{
Desiree Steppat *, Laia Castro Herrero and Frank Esser \\ Department of Communication and Media Research, University of Zurich, 8050 Zurich, Switzerland; \\ E-Mails: d.steppat@ikmz.uzh.ch (D.S.), I.castro@ikmz.uzh.ch (L.C.H.), f.esser@ikmz.uzh.ch (F.E.) \\ * Corresponding author
}

Submitted: 31 March 2020 | Accepted: 2 July 2020 | Published: 24 August 2020

\begin{abstract}
Media fragmentation and polarization have contributed to blurring the lines between professional and non-professional journalism. Internationally, more fragmented-polarized media environments are often associated with the emergence of non-professional news providers, the weakening of journalistic standards, and the segmentation of audiences along ideological leanings. Furthermore, these environments are home to partisan and alternative news media outlets, some of which try to actively undermine the credibility of traditional mainstream media in their reporting. By following an audiencecentric approach, this study investigates the consequences of more fragmented-polarized media environments and consumption habits on users' perceptions of news media performance. We use online-survey data from five countries that differ in the extent of fragmentation and polarization in the media environment $(\mathrm{CH}=1,859, \mathrm{DK}=2,667, \mathrm{IT}=2,121$, $\mathrm{PL}=2,536$, US $=3,493$ ). We find that perceptions of high news media performance are more likely to be expressed by citizens from less fragmented-polarized media environments. Positive perceptions of news media performance are also stronger among users of traditional media, and those who inform themselves in a more attitude-congruent manner. By contrast, citizens from more fragmented-polarized media environments and users of alternative news media tend to express less satisfaction with news media performance. Based on these results, we argue that perceptions of news media performance among news users are shaped by their individual media choices as well as by the composition of the news media environments that surrounds them.
\end{abstract}

\section{Keywords}

alternative media; audiences; media environment; media performance; news; online media; polarization; traditional media

\section{Issue}

This article is part of the issue "Media Performance in Times of Media Change" edited by Melanie Magin (Norwegian University of Science and Technology, Norway) and Birgit Stark (Johannes Gutenberg University Mainz, Germany).

(C) 2020 by the authors; licensee Cogitatio (Lisbon, Portugal). This article is licensed under a Creative Commons Attribution 4.0 International License (CC BY).

\section{Introduction}

When evaluating media content and performance, the perspective of media users plays an ever-increasing role in current multi-platform information environments. Greater opportunities for media audiences to make their voices heard have also meant that audiences are increasingly expressing their opinions about the quality of news and media (e.g., Dohle, 2018).
Both media quality and news media performance research consider the audience perspective as an important research approach (Maurer, 2017). Studies have found that media audiences' views are highly generalizable, and that users apply normative standards similar to those used by journalists and experts to evaluate news media performance (Neuberger, 2014; Urban \& Schweiger, 2014). Despite its undoubted relevance, research on audience perceptions and demands for high 
quality news journalism is still scarce and scattered. In particular, the antecedents of audiences' media perceptions have rarely been scrutinized.

Using the theory of subjective quality assessment (Wolling, 2009), we argue that both the structure of the media environment and the motivations and behaviors of media users influence audiences' attitudes toward the media. The present study distinguishes itself by focusing on individual and structural conditions and their influence on news media evaluations by audiences. We draw on different theoretical works that highlight the potential role of media fragmentation and polarization in decreasing journalistic quality and fueling audiences' animadversion toward the media as a whole (Mancini, 2013; Tong, 2018).

A second aim of this study is to scrutinize whether certain media use habits at the individual level (traditional, online, alternative news media use, and attitudecongruent exposure) have an impact on people's overall perceptions of the media. According to the media dependency theory, that argues that media usage shapes people's attitudes toward political institutions (Ball-Rokeach \& DeFleur, 1976), we expect media use to also explain individual attitudes toward the media as an institution (Gronke \& Cook, 2007).

To address both research aims, we conceptualize perceptions of news media performance as a multidimensional construct and test it via an online survey in five countries that differ in the extent of the fragmentation and polarization of their media environments $(\mathrm{CH}=1859, \mathrm{DK}=2667, \mathrm{IT}=2121, \mathrm{PL}=2536, \mathrm{US}=3493)$. Our results are discussed in light of their potential democratic implications in the final section of the article.

\section{Media Assessments by the Audience}

Within research on news media performance, the perspective of media users plays an ever-increasing role. Peters and Witschge $(2015$, p. 20) go so far as to postulate "[a]n audience-centred, or at least audienceinclusive, perspective on the (democratic and societal) functions of journalism is crucial if we want theory that is not only internally consistent but also aligns with-and is testable against-people's lived experiences."

New technological developments provide media users with unprecedented possibilities to express their opinions about the quality of news through, for example, reader comments or on social media (Dohle, 2018). These new possibilities put additional pressures on journalistic work, since audiences' negative evaluations of journalists' coverage can impact the public image of the news outlet for which they work (Dohle, 2018). In times of abundant media choices (Prior, 2007) and new technological possibilities to personalize media use (Peters \& Schrøder, 2018), favorable audience perceptions are crucial for the economic viability of media brands. In his theory of subjective quality assessment, Wolling (2009) stresses the importance of news outlets fulfilling audi- ences' quality expectations, since such expectations further determine future use (McQuail, 1992; Tsfati, 2010).

Given this background and contextualization, it follows that the audience perspective on news media performance is a relevant research approach (Maurer, 2017; McQuail, 1992). Nevertheless, only in recent years have audience-driven approaches been adopted more systematically for evaluating news media performance. These studies have shown that media users are well equipped to differentiate quality in news reporting and evaluate whether media content meets specific normative standards. Van der Wurff and Schoenbach (2014) found that many of citizens' expectations on news media performance align with those of experts and journalists, and what they consider main democratic functions of the media, such as journalistic independence. Heider, McCombs, and Poindexter (2005) found that audiences appreciate factual accuracy and unbiased reporting. In a similar vein, Urban and Schweiger (2014) concluded that individuals are able to recognize normative quality criteria in media content, such as impartiality or diversity. Another study on the components of 'valuable journalism' concluded that audience expectations of quality are much higher than journalists suspect, and that these audience expectations can be a helpful measure for news organizations interested in nurturing a growing, satisfied audience (Costera Meijer \& Bijleveld, 2016).

Unfortunately, research on audience perceptions of news media performance is still scarce and dispersed. In our opinion, what has received too little attention in the discussion of media evaluations by the public so far is the fact that such assessments are not free from restriction. According to the theory of subjective quality assessment (Wolling, 2009), it is, on the one hand, the external conditions set by the structure of the media environment and, on the other hand, personal characteristics of the users (e.g., their motivations and attitudes) that ultimately influence their media evaluations. These factors of influence place specific demands on research in terms of systematically investigating different media environments and determining the influence of media user personality traits on the evaluation of news media performance in the respective environments.

The present study distinguishes itself by focusing on both individual-level media habits and usage patterns, and key characteristics of the media environment (media fragmentation and polarization) and analyzing their influence on audiences' media evaluations by means of a cross-national survey.

\section{The Role of Media Fragmentation and Polarization on News Media Performance Ratings}

News media environments have undergone dramatic changes in the last two decades. Two developments are crucial in this regard: news media fragmentation and polarization. With regards to the former, in this study we define media fragmentation as the division of the 
news audience into ever-smaller groups, causing individual news outlets to lose audience shares and news users to forfeit a shared frame of reference (Geiß, Magin, Stark, \& Jürgens, 2018; Webster, 2005). Others have argued that-in particular with the emergence of online newsthe amount of political information (journalistic and nonjournalistic) that we see today is unprecedented (e.g., Neuman, Park, \& Panek, 2012; van Aelst et al., 2017). Despite the proliferation of news channels, platforms and online outlets, and the across-the-board transition from low- to so-called high-choice media environments (van Aelst et al., 2017), media fragmentation in the online domain seems to have been overestimated, however. There is still a significant share of audience duplication and overlaps between offline and online news consumption (Fletcher \& Nielsen, 2017; Weeks, Ksiazek, \& Holbert, 2016). Mukerjee, Majó-Vázquez, and GonzálezBailón (2018) find limited evidence for fragmentation in the online environment, although they identify differences between countries with the US having a seemingly more fragmented online media environment than the UK. Other studies highlight further country differences (Fletcher \& Nielsen, 2017; Majó-Vázquez, Nielsen, \& González-Bailón, 2019).

In regard to the second factor, media polarization denotes the level of political partisanship and ideological extremity of news outlets in any given news media environment (Fletcher, Cornia, \& Nielsen, 2019). Media polarization is a direct consequence of news outlet specialization based on political ideology (Gentzkow \& Shapiro, 2010) in the sense that outlets develop closer ties to certain political actors or ideologies and middle-ground news outlets loose market shares to these more partisan outlets. Numerous studies point to rather strong differences among countries when it comes to alignments between the media and the political system (Fletcher et al., 2019; Hallin \& Mancini, 2004). These differences are partly rooted in countries' differing historical paths and political systems and are changing over time. In line with Hallin and Mancini's (2004) original typology of media systems, Brüggemann, Engesser, Büchel, Humprecht, and Castro Herrero (2014) empirically showed that political parallelism is particularly strong in many Mediterranean countries, and also in certain countries in Eastern Europe (Castro Herrero, Humprecht, Engesser, Brüggemann, \& Büchel, 2017). They have also shown that levels of political parallelism serve to differentiate Scandinavian countries from other countries formerly assigned to the original Democratic Corporatist model. Similarly, while former studies attributed low levels of political parallelism to the US (Hallin \& Mancini, 2004), Nechushtai (2018) points to the fact that also the US is moving steadily towards the Mediterranean model in terms of a more polarized media system.

Overall, while evidence for both phenomena-media fragmentation and polarization-is mixed and varies across country, with cable TV and the emergence of on- line media the availability of news media sources have greatly increased (Neuman et al., 2012), and with it the availability of more politically tainted content . As previous studies showed, both phenomena-media polarization and fragmentation-are likely to develop together (Webster, 2005; Yuan, 2008), as with higher media supply news outlets are more likely to slant their reporting to attract specialized audiences (Gentzkow \& Shapiro, 2010) and audiences seek out outlets more closely related to their own political convictions (Stroud, 2011).

Also relevant for the purposes of this study, it has been shown that both phenomena go hand-in-hand with a decline in objective news reporting and a softening of traditional journalistic standards (Mancini, 2013). We therefore argue that the intertwining of media fragmentation and polarization contribute to undermining positive perceptions of news media performance in two ways. First, more fragmented-polarized media environments add to an actual decline of news media performance. Shrinking audience shares increase the economic hardships of news outlets. The loss in financial revenues has tangible consequences for news media performance, such as decreasing topic diversity and impartiality and an orientation toward popularization (Scott, 2005; Umbricht \& Esser, 2016). Furthermore, with a multiplication of information sources, audience's tastes play a more crucial role than ever before. Indeed, media polarization arises as a result of news outlets targeting audiences with distinct political preferences (Stroud, 2011). Tong (2018) points out a dilemma: Journalism can only lose in times of political polarization because news outlets either have to abandon the principle of objectivity or endure harsh criticism by, for example, political activists without fighting back. These repeated attacks on their integrity may well damage their reputation in the public eye. Particularly in times of increased political polarization, news outlets seem to follow the strategy of adopting more partisan positions and abandoning the ideal of objectivity in favor of biased reporting (Gentzkow \& Shapiro, 2010). This is relevant for our study since previous research posits that satisfaction with news media performance is in part a reflection of how neutral and objective media is perceived to be (Towner \& Lego Munoz, 2016).

Second, more fragmented-polarized media environments contribute to a perceived decline in media quality by facilitating the emergence of both so-called alternative and hyper-partisan news media sources (Ladd, 2011). Hyper-partisan news sources tend to be blatantly opinionated and less professionalized, thereby eroding journalists' traditional values and challenging journalistic legitimacy (Tong, 2018). While alternative news media tend to openly position themselves as the antithesis of the mainstream media, and degrade the mainstream media as lapdogs to the political establishment (Figenschou \& Ihlebæk, 2019). Thus, a more fragmentedpolarized media environment can promote negative perceptions of news media performance in both direct and indirect ways. 
Nevertheless, it is important to note that these two processes (trends of media fragmentation and polarization) have not taken place at the same speed and to the same extent across different news media environments (Fletcher et al., 2019; Fletcher \& Nielsen, 2017). Media use research has long neglected the crucial role of information environments in offering varying boundary conditions for individual-level news consumption processes (Boomgaarden \& Song, 2019). We account for the close link between micro and macro factors by looking at news users' perceptions of news media performance in information environments that differ in the extent of their media fragmentation and polarization. With reference to the theoretical considerations outlined above, we expect that:

$\mathrm{H} 1$ : Perceptions of news media performance are more negative among news users in more fragmentedpolarized media environments.

\section{Media Use Habits on Individuals' Satisfaction with News Media Performance}

Drawing on media dependency theory (Ball-Rokeach \& DeFleur, 1976), we further argue that the media sources people use and pay attention to crucially explain their political attitudes and, by extension, their loyalties toward and perceptions of the media as a whole (Gil de Zúñiga \& Hinsley, 2013; Towner \& Lego Munoz, 2016). In the following, we delve into the characteristics of distinct media types and attitude-congruent news-use patterns and present some expectations regarding how individuals' media use shapes their evaluations of news media performance.

\subsection{Use of Different Media Types}

Previous research has highlighted the importance of traditional, well-established media brands in perceptions of media quality (McDowell, 2011; Urban \& Schweiger, 2014). Comparing different traditional and online news formats, Neuberger (2014) showed that news users rate traditional news sources significantly higher in terms of objectivity, independence, and audience orientation. By contrast, audiences do not associate online news sources relying on user-generated content with practices of 'good journalism' (Gil de Zúñiga \& Hinsley, 2013). Most importantly, Gil de Zúñiga and Hinsley (2013) provided support for the assumption that using more traditional and professionalized media sources actually leads to higher media trust and more positive perceptions toward the media in general by enhancing people's beliefs that media coverage attains standards of good journalism (Gil de Zúñiga \& Hinsley, 2013; see also Newman, Fletcher, Kalogeropoulos, \& Nielsen, 2019). Neuberger (2014) also found that social media sources in particular have been linked to more negative evaluations of news media performance. In a similar vein, different studies found a negative relationship between newsrelated social media use and satisfaction with news media performance-partially due to uncivil or negative commenting on news stories by social media users (Dohle, 2018).

Greater media skepticism and negativity toward journalism are also associated with the use of more antiestablishment and advocative media sources that label themselves as 'alternative' to the mainstream media (Figenschou \& Ihlebæk, 2019). Alternative news media outlets tend to present themselves as counter-discursive, counter-hegemonic and antithetic to the mainstream media (Atton, 2015). As outlined earlier, they also challenge journalistic legitimacy by providing a platform for voices not represented in mainstream media coverage and blaming mainstream journalism for their purported negligence in this regard (Figenschou \& Ihlebæk, 2019).

Drawing on the media dependency theory, we posit that media users assess the performance of the media in general from the perceived performance of the media types they use. In particular, we expect media users who rely on high-performing media products (such as established news brands) to apply this higher quality assessment in their evaluations of the media in general (Gil de Zúñiga \& Hinsley, 2013). Against the backdrop of previous research findings, we hypothesize:

H2: Perceptions of news media performance are more positive among users of traditional news media.

Accordingly, it follows that users of media sources that show lower performance in their content (such as onlineonly sources and social media) should appraise overall news media performance more negatively. Thus, we hypothesize:

H3: Perceptions of news media performance are more negative among users of online news media.

Due to the specific character of alternative news media as a self-perceived corrective to the media in general (Holt, Figenschou, \& Frischlich, 2019) and their (overall) less professionalized character (Atton, 2015), we expect their users to perceive the media in an overall more negative light. Consequently, we formulate the following hypothesis:

H4: Perceptions of news media performance are more negative among users of alternative news media.

\subsection{Use of Attitude-Congruent Contents}

We expect attitude-congruent media use-meaning the use of information that is in line with one's views-to enhance more positive views of news media performance among the public. One reason is that individuals' satisfaction with news media performance is often associated with how neutral and objective media is perceived to be 
(Towner \& LegoMunoz, 2016). Individuals tend to perceive information as biased when it does not support their position, and as balanced when the information aligns with their views (Gunther, Edgerly, Akin, \& Broesch, 2012). Previous research has also shown that individuals who use attitude-congruent information further evaluate this information be to of higher quality (Greitemeyer \& Schulz-Hardt, 2003) and attribute greater 'news-ness' to congenial rather than uncongenial sources (Edgerly \& Vraga, 2020). We therefore hypothesize that:

H5: Perceptions of news media performance are more positive among users who inform themselves more attitude-congruently.

\section{Operationalizing Perceptions of News Media Performance}

Media performance can be understood as an indicator of how well media is serving the public interest (McQuail, 1992). While McQuail (1992) refers to the overall media, he especially highlights the important role played by news media to contribute to an informed public. Different operationalizations of news media performance using various empirical dimensions have been put forth from multiple disciplines. Stemming from an audience-driven perspective, we measure individuals' perceptions of news media performance across four of those dimensions, which we label 'diversity,' 'representation,' 'objectivity,' and 'journalistic independence.' Our approach is informed by three strands of literature, namely (a) media policy and institutionalist perspectives focusing on democratic functions of the media (McQuail, 1992; Tuchman, 1980), (b) empirical studies that extend their theorizing with surveys and experimental research using audience perceptions of news media (Heider et al., 2005; Neuberger, 2014; Urban \& Schweiger, 2014), and (c) surveys from journalists capturing their dictates and professional norms when covering news (Hanitzsch \& Berganza, 2012).

First, research in the domain of media policy has investigated media 'diversity' by scrutinizing "the variety or breadth of media content available to media consumers, with higher consumer welfare provided by high diversity" (Rössler, 2007, p. 467). From a normative standpoint, media diversity serves to indicate how well media functions as a marketplace of ideas that represents all relevant issues and voices within a society (Jandura \& Friedrich, 2014). A diverse media environment enables citizens to be attuned to different opinions and reevaluate their own (Napoli, 2011). Research has mainly looked at two components of media diversity: source and content diversity. While source diversity deals with the presence of different types of media outlets within a particular media market, content diversity specifically considers whether different topics are discussed in the news or whether different viewpoints are presented (Napoli, 2011).
Second, news media 'representation' indicates an orientation toward the audience and a consideration of their concerns and opinions in news coverage. News media representation accounts for the representation function of the media and its ability to convey the publics' opinions to those in power (Curran, 2005). Van der Wurff and Schoenbach (2014) have shown that news users perceive journalism to be performing well when reporting on issues and events close to their everyday life. Feeling involved in news making is particularly important in times of increased news choices where audience preferences matter more in guiding choices (Prior, 2007). While inclusion of the audience can vary in its degree (Peters \& Witschge, 2015), we argue that a minimal understanding of representation entails depiction of issues and opinions members of the audience hold important (Neuberger, 2014), as well as the availability of news outlets that represent their views (Costera Meijer \& Bijleveld, 2016). In McQuail's (1992) theoretical model, representation or representativeness is part of media diversity. In our analysis, representation of the audience emerges as an independent factor (see results section).

Third, 'objectivity' refers to the journalistic norm of depicting reality as faithfully and accurately as possible. Journalists who follow this standard report on events without being influenced by their own opinions or interests (Schudson, 2001; Tuchman, 1980). In countries with long-standing traditions of objective news reporting, the public agenda is less restricted to those more divisive issues of the day, and more concerned with the most societally relevant and consequential policy issues and actors, thereby contributing to political institutions that are high functioning and responsive. Scholars have agreed on certain key features that characterize objectivity as a defining character of media that is performing well. According to Westerståhl (1983), objectivity in news reporting contains four components: truthful reporting, relevance, balance, and a neutral presentation of facts. Following Schudson (2001), objectivity is synonymous with factual, unemotional, and impartial reporting.

Finally, 'journalistic independence' is another key cornerstone of any healthy democracy and is inherent in the notion of press freedom. Following McQuail (1992), independent journalists render political elites accountable and act as a watchdog of those in power. They are free from political and economic interference and refrain from expressing any partisan affiliations (Hanitzsch \& Berganza, 2012). Journalistic independence is therefore strongly intertwined with the other three dimensions of media performance (diversity, representation, and objectivity) outlined above. Absence of government interference ensures diverse reporting, allows media to voice citizens' demands, and serve as a free intermediary between ordinary citizens and those in power (Curran, 2005). Through the adherence to professional standards such as the objectivity principle, the media further establishes its legitimacy as an independent institution (Tong, 2018). 


\section{Method}

As argued above, we anticipate that media environments are important factors that shape citizens' perceptions of news media performance. In the following section, we therefore describe our selection of countries before turning to the data description and measures used to test our hypotheses.

As a first set of countries, we identified Italy, Poland, and the US. These three countries have relatively large and highly commercialized media markets. Public service media either plays a peripheral role (US) or is highly tainted by political interference (Italy and Poland; Esser et al., 2012; Newman et al., 2019). Alternative and partisan news sources are strong in all three cases (Mancini, 2013; Mocek, 2019; Nechushtai, 2018). Media environments in the second set of countries-Denmark and Switzerland-share many commonalities: Their markets are small in size, and are characterized by a high distribution of catch-all media with little partisan leanings (Marquis, Schaub, \& Gerber, 2011; Nord, 2016), and a strong press and public service media sector (Hallin \& Mancini, 2004).

To test our hypotheses, we conducted an online survey among $\mathrm{N}=12,676$ news users in five countries $(\mathrm{CH}=1,859 ; \mathrm{DK}=2,667 ; \mathrm{IT}=2,121 ; \mathrm{PL}=2,536$; US $=3,493)$ in July 2018. Participants were recruited from an online access panel following a quota procedure regarding sex, age, and education of the individual national population above 18 years of age $\left(\mathrm{CH}: \mathrm{M}_{\text {age }}=53.5\right.$, $\mathrm{SD}=14.6,55 \%$ female; $\mathrm{DK}: \mathrm{M}_{\text {age }}=50.3, \mathrm{SD}=14.9,51.8 \%$ female; IT: $M_{\text {age }}=47.9, S D=13.9,47.2 \%$ female; $P L$ : $M_{\text {age }}=42.7, S D=14.2,51.8 \%$ female; US: $M_{\text {age }}=50.5$, $\mathrm{SD}=14.5,51.3 \%$ female).

\subsection{Measures}

\subsubsection{Perceived News Media Performance}

We asked news users to rate several statements about their respective media environments on a 5-point Likert scale ranging from 1 (strongly disagree) to 5 (strongly agree). Via confirmatory factor analysis, we identified four indicators corresponding to the four dimensions of media performance outlined above-diversity, objectivity, representation, and journalistic independence (see the following section for a step-by-step description of this analysis). Table 1 shows item wordings of all perceived news media performance indicators with their respective reliability scores. All four indicators were combined into a mean-score index to evaluate perceived news media performance $(M=3.03$; $S D=.80$; Cronbach's $\alpha=.73$ ).

\subsubsection{Media Fragmentation and Polarization}

To test the effect of varying degrees of fragmentation and polarization in each media environment, we constructed a combined index with five indicators (media fragmentation: news media market size, shared news, share of public service broadcaster; media polarization: political parallelism and audience polarization-for details on the respective indicators see the Supplementary File). For each indicator, we ranked the five media environments according to their values. Subsequently, we calculated a mean score index of the ranks of the five indicators. Ranks have been inverted so that higher values mean, for example, bigger active news user markets, less shared news, and smaller public service broadcaster audience share. This way, higher numbers stand for higher lev-

Table 1. Item wording of media performance indicators.

\begin{tabular}{|c|c|c|c|c|}
\hline Item & Wording & M & SD & $\begin{array}{l}\text { Cronbach's } \alpha / \\
\text { Spearman-Brown } \rho\end{array}$ \\
\hline $\operatorname{div} 1$ & Compared with other countries, the media in [country] are very diverse & \multirow{3}{*}{3.37} & \multirow{3}{*}{.94} & \multirow{3}{*}{.74} \\
\hline $\operatorname{div} 2$ & Media in [country] handle a lot of different topics & & & \\
\hline div3 & $\begin{array}{l}\text { Media in [country] take great care in examining political issues from } \\
\text { different sides }\end{array}$ & & & \\
\hline rep1 & $\begin{array}{l}\text { In [country], a large selection of media is available to me that represent } \\
\text { political views that are similar to my own }\end{array}$ & \multirow{2}{*}{3.15} & \multirow{2}{*}{.99} & \multirow{2}{*}{.74} \\
\hline rep2 & $\begin{array}{l}\text { I have the feeling that my own opinion is represented often in the media } \\
\text { in [country] }\end{array}$ & & & \\
\hline jouin1 & The media in [country] are influenced by political elites [inverted] & \multirow{2}{*}{2.22} & \multirow{2}{*}{.95} & \multirow{2}{*}{.75} \\
\hline jouin2 & The media in [country] are full of partisan statements [inverted] & & & \\
\hline obj1 & The media in [country] report impartially & \multirow{4}{*}{2.79} & \multirow{4}{*}{.79} & \multirow{4}{*}{.71} \\
\hline obj2 & The media in [country] report without errors & & & \\
\hline obj3 & Media in [country] always clearly differentiate between news and opinions & & & \\
\hline obj4 & Media in [country] rely on arguments instead of emotions & & & \\
\hline
\end{tabular}


els of media fragmentation and polarization $(\mathrm{CH}=1.42$; $\mathrm{DK}=1.42 ; \mathrm{PL}=3.42 ; \mathrm{IT}=4.09 ; \mathrm{US}=4.5$ ).

\subsubsection{Media Type Use}

Respondents' use of different media types was assessed through a dichotomous variable. Participants were asked whether they used a particular type of media source ( $1=$ yes, $0=$ no). They could select from four different media types (TV, newspaper, online-only, and social media). Participants could choose multiple media sources (76.8\% of participants used TV, $52.5 \%$ newspapers, $37.8 \%$ social media, and $36.3 \%$ online-only).

To measure alternative news media use, we asked participants whether they seek out alternative sources of information to contrast mainstream news reporting in order to receive a more all-encompassing version of events on a 4-point scale ( 1 = 'no, not at all,' 2 = 'no, mostly not,' $3=$ 'yes, mostly,' 4 = 'yes, definitely'). This operationalization resonates with the most recent definition for alternative news media provided by who characterize alternative news media as correctives to mainstream media. Responses 1 to 2 were then recoded as 0 (49.9\%), while responses 3 to 4 were recoded as 1 (50.1\%). Exact question wording can be found in the Supplementary File.

\subsubsection{Attitude-Congruent Media Exposure}

In addition to media source types, we asked participants to indicate which specific news outlets they regularly use and to rate all outlets on a standard 11-point left-right ideological scale (Goldman \& Mutz, 2011). We later subtracted the scores for the news outlets from the participants' own left-right self-placement and built a meanscore index (Cronbach's $\alpha=.91$ ). This indicator accounts for the overall distance news users perceive between their own attitudes and the perceived political positions advocated by the news media they use independent of participants' own political orientation. The scores were inverted to facilitate interpretation, so that higher numbers indicate high agreement between the political position of the participant and the media sources (s)he uses $(\mathrm{M}=7.6, \mathrm{SD}=1.7)$.

We furthermore controlled for demographics (sex, age, and education), political interest, interest in news, left-right political orientation, and political extremity (for a more detailed description of their operationalization see the Supplementary File).

\section{Results}

One of the main aims of this article is to compare news media performances evaluations across countries. For this purpose, it is important to ensure that any model used is applicable in different cultural contexts (Davidov, 2009). Before turning to our hypotheses, we therefore tested whether our model with four indicatorsdiversity, objectivity, representation, and journalistic independence-measures the underlying constructnews media performance-equally well in all five countries considered.

\subsection{Establishing Measurement Invariance for News Media Performance}

To verify measurement invariance, we conducted both confirmatory factor analysis and multi-group confirmatory factor analysis. Our assessment of measurement invariance followed four steps: First, we established with the pooled dataset whether the model with four distinct endogenous variables (diversity, objectivity, representation, and journalistic independence) fits the data better than a one-factor solution. Second, we tested whether our proposed model with four factors describes the exogenous variable news media performance equally well across all five country contexts (configural invariance). Last, we tested for metric and scalar invariance across the different country contexts to be able to compare group means.

To test whether the four factors we identified (diversity, representation, objectivity, and journalistic independence) define the outcome variable 'news media performance' more accurately than a one-factor solution, we used AMOS 25.0.0 and calculated a confirmatory factor analysis using maximum likelihood estimation. Compared to the one-factor solution (RMSEA = .121; $\mathrm{CFI}=.900$ ) the four-factor solution (Figure 1) displays a much better model fit (RMSEA $=.055 ; \mathrm{CFI}=.984)$. Our four-factor model lies within the proposed limits by $\mathrm{Hu}$ and Bentler (1999) who suggest a RMSEA $\leq .060$ and a $\mathrm{CFI} \geq .950$ as a good model fit. We also tested a threefactor model with diversity and representation indicators constituting one factor. This model showed a poorer fit in comparison with the four-factor model (CFI = .902; RMSEA $=.63$ ), suggesting that the model put forth by McQuail (1992) needs to be extended by making representation an independent factor aside from the diversity domain.

In a next step, we applied multi-group confirmatory factor analysis by using our five countries as groups to test whether the proposed factor structure is identical across the different subsamples. Table 2 shows that across all five countries, the four-factor model demonstrates a good fit within the proposed boundaries (Hu \& Bentler, 1999). Only exception is the RMSEA for Poland, in which RMSEA $=.072$ slightly exceeds the proposed limits by . Nevertheless, the CFI for our proposed model with the Polish subsample is well above the proposed threshold of CFI $\geq .950$. This result can be seen as a proof for configural invariance (Steenkamp \& Baumgartner, 1998).

In a third step, we looked at metric invariance. Metric invariance ensures that citizens from different countries have an equal understanding of the individual survey items. To test whether our model demonstrates measurement invariance across the five different countries, we restricted the factor loadings between each item 


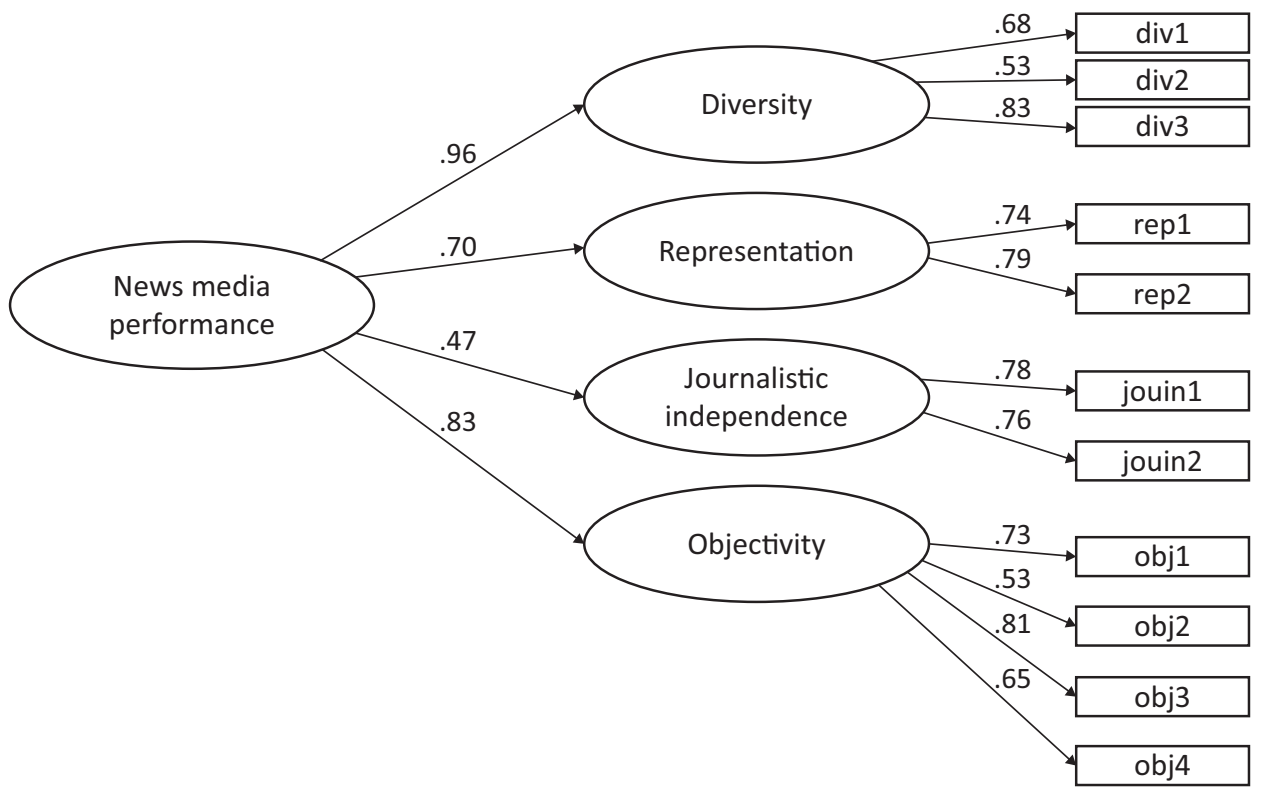

Figure 1. Confirmatory factor analysis with indicators for perceived news media performance.

and the respective construct they are supposed to measure (diversity, objectivity, journalistic independence, and representation). Due to the large sample size, multigroup confirmatory factor analysis is likely to overestimate differences between constraint and unconstraint models (Davidov, 2009). Thus, we relied on Chen's (2007) recommendation to compare RMSEA and CFI between models. An indication of lack of invariance can be detected when the RMSEA rises more than .015 units and the CFI exceeds .010 when comparing between constraint and unconstrained models (Chen, 2007). With a $\triangle \mathrm{RMSEA}=-.007$ and a $\triangle \mathrm{CFI}=.000$, our model demonstrates metric invariance (see Table 2).

Lastly, to measure scalar invariance, we also compared fit indices of our model after additionally constraining the intercepts. Establishing scalar invariance allows us to substantiate multi-group comparisons of factor means, so we can confidently interpret statistically significant differences between group means. Here, the picture is less clear than for the metric invariance: The CFI decreases by .065 , nevertheless the RMSEA is .040, well below the conventional threshold of $\leq .060$. Additionally, the value of RMSEA drops by .015, which still lies within the proposed threshold (Chen, 2007). We interpret these results as support that our proposed model also demonstrates scalar invariance.

News media performance evaluation is measurable across countries. Our confirmatory factor analysis shows a good fit for the presumed model. Multi-group confirmatory factor analysis furthermore demonstrates that the presumed model exhibits a good fit within different country contexts, as well as metric and scalar invariance which allows for cross-country comparison (Chen, 2007; Steenkamp \& Baumgartner, 1998).

\subsection{Cross-National and Individual Differences in Perceptions of News Media Performance}

We first have a closer look into how our dependent variable performs across the five countries considered. For this, we compared the individual countries in their assessment of the four factors constituting news media performance in this study. As we can see in Figure 2, our countries cluster in two distinct groups: On the one hand,

Table 2. Model fit indices for different steps to determine measurement invariance.

\begin{tabular}{|c|c|c|c|c|c|c|c|}
\hline Model & $\mathrm{N}$ & Chi2 & $d f$ & $\mathrm{CFI}$ & RMSEA & $\Delta \mathrm{CFI}$ & $\triangle \mathrm{RMSEA}$ \\
\hline Pooled & 12,676 & 473.57 & 12 & .984 & .055 & & \\
\hline \multicolumn{8}{|l|}{ Invariance: } \\
\hline Configural & 12,676 & 544.87 & 60 & .983 & .025 & & \\
\hline Metric & 12,676 & 801.311 & 88 & .976 & .025 & -.007 & .000 \\
\hline Scalar & 12,676 & 2747.51 & 132 & .911 & .040 & -.065 & -.015 \\
\hline DK & 2,667 & 116.621 & 12 & .981 & .057 & & \\
\hline $\mathrm{CH}$ & 1,859 & 76.58 & 12 & .981 & .054 & & \\
\hline IT & 2,121 & 87.778 & 12 & .985 & .055 & & \\
\hline PL & 2,536 & 169.061 & 12 & .973 & .072 & & \\
\hline US & 3,493 & 94.828 & 12 & .991 & .044 & & \\
\hline
\end{tabular}




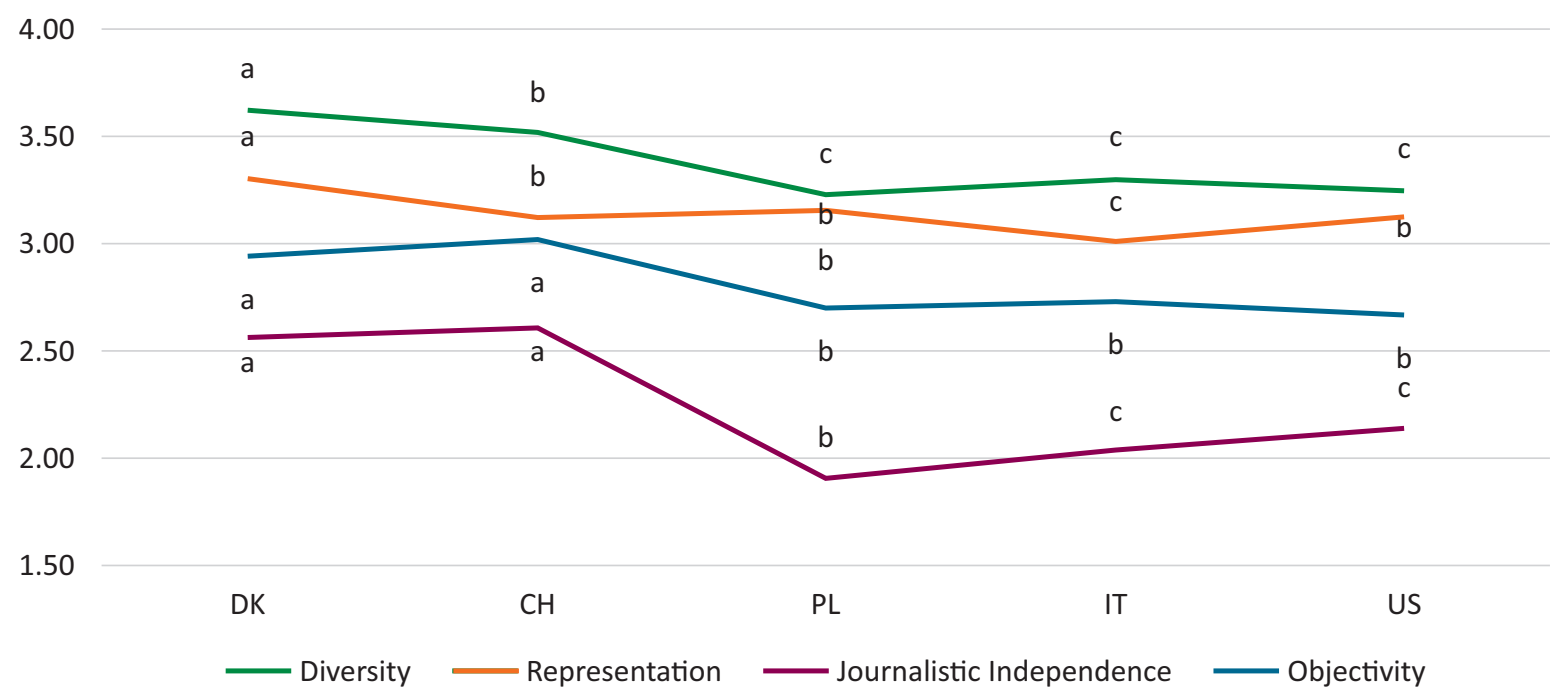

Figure 2. Countries differences in perceived news media performance by individual indicators. Note: Groups with different identification letters $(a, b, c)$ are significantly different according to Bonferroni-corrected post hoc tests $(p<.05)$.

$\mathrm{CH}$ and DK with the most positive evaluations across all four indicators, and on the other hand, $\mathrm{PL}, \mathrm{IT}$, and the US with overall lower values on all four indicators. Respondents in PL, IT and US are particularly critical of the performance indicators objectivity and journalistic independence in comparison to news users in DK and $\mathrm{CH}$. The picture looks different for the other two factors, diversity and representation, where country differences are less clear between the two groups. Overall, diversity receives the highest audience ratings across all countries on a 5-point scale $\left(\mathrm{M}_{\mathrm{DK}}=3.62 ; \mathrm{M}_{\mathrm{CH}}=3.52 ; \mathrm{M}_{\mathrm{PL}}=3.23\right.$; $\mathrm{M}_{\mathrm{IT}}=3.30 ; \mathrm{M}_{\mathrm{US}}=3.25$ ).
For explaining differences across countries and media use types, we estimated a cluster bootstrapped regression with 1,000 replications (clustered on countries) using the 'bootcov' function in the 'rms: Regression Modeling Strategies' package (Harrell, 2019) in R. This solution allows to account for the nested structure of our data and the small cluster number with only five cases (Huang, 2018).

Results of the regression analysis are summarized in Table 3. H1 stated that news users in more fragmentedpolarized countries perceive the media as performing more poorly. This expectation is clearly confirmed. We

Table 3. Cluster bootstrapped regression model predicting media performance.

\begin{tabular}{|c|c|c|c|}
\hline & & B & SE B \\
\hline & (Constant) & 2.725 & .091 \\
\hline \multicolumn{4}{|l|}{ Controls } \\
\hline & Sex [baseline male] & .013 & .047 \\
\hline & Education & $-.042+$ & .022 \\
\hline & Age & $-.005 *$ & .002 \\
\hline & Political interest & -.034 & .033 \\
\hline & Interest in political news & $.073 *$ & .036 \\
\hline & Political orientation & .004 & .016 \\
\hline & Political extremity & .008 & .017 \\
\hline \multicolumn{4}{|l|}{ Predictors \#1 to \#5 } \\
\hline & User in more fragmented-polarized media environments & $.073 *$ & .025 \\
\hline \multirow[t]{2}{*}{ Traditional media } & User of TV & $.105 * *$ & .032 \\
\hline & User of print newspaper & $.115^{*}$ & .036 \\
\hline \multirow[t]{4}{*}{ Online media } & User of online-only news & -.041 & .045 \\
\hline & User of social media & -.005 & .022 \\
\hline & User of alternative news media & $-.341 * * *$ & .063 \\
\hline & User of attitude-congruent media & $.116 * * *$ & .014 \\
\hline$N$ & & \multicolumn{2}{|c|}{12469} \\
\hline$R^{2}$ & & \multicolumn{2}{|c|}{.180} \\
\hline$F$ & & \multicolumn{2}{|c|}{$670.56 * * *$} \\
\hline
\end{tabular}

Notes: Estimates are unstandardized coefficients (B) with standards errors (SE B). ${ }^{* *} p<.001,{ }^{* *} p<.01,{ }^{*} p<.05,+p<.1$ (two-tailed). 
find a negative relationship between the level of fragmentation and polarization in the media environment and the evaluation of the news media performance $(b=-.073, S E=.025, p<.05)$. Put differently: The varying levels of fragmentation and polarization are an important factor explaining why citizens in the two country groups rate news performance so differently.

$\mathrm{H} 2$ and $\mathrm{H} 3$ were concerned with the use of traditional and online media types on perceptions of news media performance. We find that using traditional media, such as TV ( $b=.105$, SE $=.032, p<.01)$ and newspapers $(b=.115, S E=.036, p<.05)$ increase one's likelihood of holding more positive perceptions of news media performance, as hypothesized $(\mathrm{H} 2)$. The use of online media, by contrast, has no positive influence on the appreciation of news media performance in one's own country. However, the negative relationships we find between the general evaluation of news media performance, on the one hand, and news usage on online-only $(b=-.041$, $\mathrm{SE}=.045, \mathrm{p}>.05)$ and social media channels $(b=-.005$, $\mathrm{SE}=.022, \mathrm{p}>.05)$, on the other hand, do not reach significance. Therefore $\mathrm{H} 3$ is not confirmed. Turning now to $\mathrm{H} 4$, we expected use of alternative news media would be detrimental to satisfaction with news media performance, and, indeed, we find a negative relationship between using alternative news media sources and perceiving the media as performing well $(b=-.341, \mathrm{SE}=.063$, $p<.001)$. With regards to our last hypothesis, we find that attitude-congruent media exposure in the everyday media diet has a positive effect on the perception of news media performance $(b=.116, \mathrm{SE}=.014, \mathrm{p}<.001)$, as anticipated (H5).

\section{Conclusion}

Audiences' perceptions of how the media performs its societal role are crucial in understanding why citizens use or do not use various news sources. What people think of and expect from their country's news media influences long-term patterns of news use (Tsfati, 2010; Wolling, 2009) and thus the media's ability to contribute to an informed public sphere and engaged citizenship in that country (Delli Carpini \& Keeter, 1996). In this article, we acknowledge the importance of the media user's perspective and test whether factors in individual media use and in the media environment shape perceptions of four key dimensions of news media performance (diversity, representation, objectivity, and journalistic independence) among respondents to a cross-national online survey.

Previous studies building on content analysis revealed that new trends brought about by media fragmentation and polarization (rise of less professionalized sources, increased popularization, and antiestablishment discourses) have impacted actual news performance by, for example, undermining diverse and objective news reporting (Benson, Blach- $\varnothing$ rsten, Powers, Willig, \& Zambrano, 2012; Umbricht \& Esser, 2016). Our study demonstrates that users' evaluations of news media performance in different media environments come to similar conclusions as studies looking at actual media content. This further underlines the aptness of audiencecentered approaches in the assessment of news media performance for future comparative research projects.

Comparing media environments, we find the perception of news media performance differs significantly in two groups of countries with different levels of media fragmentation and polarization. In particular, the higher the level of fragmentation and polarization, the worse the perceived news performance, especially with regard to journalistic independence and objectivity. This clearly applies to Poland, Italy and the US. In the same breath, however, we would like to emphasize that for the other two dimensions of news performance, diversity and representation, we do not see fundamentally different assessments in the two country groups. Perceptions of whether the news media are pluralistic and whether one's own views are represented in the news seem to develop more independently of whether citizens live in more or less fragmented-polarized media environments. This is different for the perception of objectivity (how impartial, factual, neutral, and substantial the news are) and journalistic independence (how unaffected from parties and political powers the news are). Regarding these two factors, citizens in the two country groups (more and less polarized media environments) see clear differences. Our argument that this is linked to varying degrees of national media fragmentation and polarization fits well with Mancini's (2013) line of thought, as objectivity and journalistic independence are more tied to each countries' levels of political interference on the media and varying journalistic standards. By contrast, perceptions of diversity and representation seem to depend less on factors bound to traditional media environments due to increased platformization of the news and global trends in online news consumption (Flew \& Waisbord, 2015; Newman et al., 2019).

Our results further show that using traditional media such as TV or newspapers enhance user satisfaction with news media performance. This is particularly comforting as traditional media are still among the most frequently used news sources in most countries (Newman et al., 2019). We find no such effect for online-only news sources and social media use for news. Our findings also reveal that higher levels of attitude-congruent media exposure make for more positive assessments of news media performance. To date, research has shown that users of opinion-congruent information perceive the very same information as high quality (Greitemeyer \& Schulz-Hardt, 2003). Our research further shows that this effect can be extended to the evaluation of the news media in general. This finding has important implications. As Goldman and Mutz (2011) have already pointed out, people tend to perceive media sources as 'friendlier' when they are closer to one's own opinion. While citizens who inform themselves attitude-congruently per- 
ceive the media they use to be impartial, balanced, and diverse-as Goldman and Mutz elaborate-the information they receive might actually not reflect these characteristics. In the long run, this might increase perceived quality gaps between like-minded and non-like-minded information and make citizens judge non-like-minded information more defensively and critically.

Interestingly, while more attitude-congruent media exposure increases perceptions of the media to perform well, we find the opposite trend for other media sources that similarly depart from journalistic standards of impartiality. The use of alternative news media sources seems to promote people's image that the news media performs poorly. The underlying explanation in this case may not be rooted in spillovers from people's evaluations of their news diets to their evaluations of the media in general. For alternative news media users, another reason may come to the fore: The representation of 'the' media in actual coverage of such alternative news media sources is explicitly negative (Figenschou \& Ihlebæk, 2019).

Our study is not without limitations. While our operationalization of perceived news media performance is grounded in a wide range of well-established studies from different communication fields, it is just one of many possibilities. By analyzing other indicators of news media performance (e.g., analytical depth or topicality), one might potentially come to different conclusions. Since the focus of this study lies in identifying differences in news media performance evaluations across countries, we have deliberately opted for an overarching, holistic judgment (similar to Gil de Zúñiga \& Hinsley, 2013), by asking participants to rate performance of the media in their country. This approach, however, leaves room for interpretation on the part of the individual respondent regarding what constitutes news media, which we cannot control conclusively. Nor do we have the means to compare answers to the same question for 'the' media, 'mainstream' media, or the media 'used' by a respondent. Even though recent studies provide evidence that news users have a rather traditional and common view on what is news and what not (Hartley, 2018), particularly in fragmented-polarized media environments, what exactly constitutes news media might differ greatly depending on who is being asked (Daniller, Allen, Tallevi, \& Mutz, 2017). Future studies need to investigate this differentiation more closely, however, by using a broader range of fine-grained indicators of perceived news media performance. Relatedly, while our operationalization of alternative news media use relies on recent theoretical approaches characterizing alternative news media as correctives to the mainstream (e.g., Holt et al., 2019), it is not without shortcomings. To our knowledge, our study is the first to actually investigate perceived news media performance among alternative news media users. However, neither our question wording nor our crosssectional design are able to elucidate whether it is the content of alternative news media or the motives to use them (i.e., higher animadversion toward mainstream media) what erodes overall trust and satisfaction with the media. Similarly, our study only allows us to take a snapshot at country differences in terms of media fragmentation and polarization; a larger country sample and longitudinal data would be needed to observe the extent and implications of these trends in more depth.

Taken together, our findings suggest that both individual use patterns and contextual factors (media fragmentation and polarization) affect people's perceptions of media quality and performance. Whereas media users make inferences from their everyday news diets to the news media in general, they also seem to be able to identify actual across-the-board decreases in journalistic quality in those systems where diverse, objective, representative, and independent media coverage is compromised (i.e., in more fragmented-polarized media environments). More research lies ahead to determine the potential of traditional news media to mitigate negative media perceptions that come with increasingly fragmentedpolarized and multi-platform media environments.

\section{Acknowledgments}

This study was supported by from the Swiss National Science Foundation (project grant number: 100017_173286).

\section{Conflict of Interests}

The authors declare no conflict of interests.

\section{Supplementary Material}

Supplementary material for this article is available online in the format provided by the author (unedited).

\section{References}

Atton, C. (Ed.). (2015). The Routledge companion to alternative and community media. New York, NY: Routledge.

Ball-Rokeach, S. J., \& DeFleur, M. L. (1976). A dependency model of mass-media effects. Communication Research, 3(1), 3-21.

Benson, R., Blach- $\varnothing$ rsten, M., Powers, M., Willig, I., \& Zambrano, S. V. (2012). Media systems online and off: Comparing the form of news in the United States, Denmark, and France. Journal of Communication, 62(1), 21-38.

Boomgaarden, H. G., \& Song, H. (2019). Media use and its effects in a cross-national perspective. Kölner Zeitschrift Für Soziologie Und Sozialpsychologie, 71, 545-571.

Brüggemann, M. L., Engesser, S., Büchel, F., Humprecht, E., \& Castro Herrero, L. (2014). Hallin and Mancini revisited: Four empirical types of Western media systems. Journal of Communication, 64(6), 1037-1065. 
Castro Herrero, L., Humprecht, E., Engesser, S., Brüggemann, M. L., \& Büchel, F. (2017). Rethinking Hallin and Mancini beyond the West: An analysis of media systems in Central and Eastern Europe. International Journal of Communication, 11(27), 4797-4823.

Chen, F. F. (2007). Sensitivity of goodness of fit indexes to lack of measurement invariance. Structural Equation Modeling: A Multidisciplinary Journal, 14(3), 464-504.

Costera Meijer, I., \& Bijleveld, H. P. (2016). Valuable journalism: Measuring news quality from a user's perspective. Journalism Studies, 17(7), 827-839.

Curran, J. (2005). Mediations of democracy. In J. Curran \& M. Gurevitch (Eds.), Mass media and society (4th ed., pp. 122-149). London: Hodder Education.

Daniller, A., Allen, D., Tallevi, A., \& Mutz, D. C. (2017). Measuring trust in the press in a changing media environment. Communication Methods and Measures, 11(1), 76-85.

Davidov, E. (2009). Measurement equivalence of nationalism and constructive patriotism in the ISSP: 34 countries in a comparative perspective. Political Analysis, 17(1), 64-82.

Delli Carpini, M. X., \& Keeter, S. (1996). What Americans know about politics and why it matters. New Haven, CT: Yale University Press.

Dohle, M. (2018). Recipients' assessment of journalistic quality: Do online user comments or the actual journalistic quality matter? Digital Journalism, 6(5), 563-582.

Edgerly, S., \& Vraga, E. K. (2020). That's not news: Audience perceptions of 'news-ness' and why it matters. Mass Communication and Society. Advance online publication. https://doi.org/10.1080/15205436. 2020.1729383

Esser, F., de Vreese, C. H., Strömbäck, J., van Aelst, P., Aalberg, T., Stanyer, J., . . . Reinemann, C. (2012). Political information opportunities in Europe: A longitudinal and comparative study of thirteen television systems. The International Journal of Press/Politics, 17(3), 247-274.

Figenschou, T. U., \& Ihlebæk, K. A. (2019). Challenging journalistic authority: Media criticism in farright alternative media. Journalism Studies, 20(9), 1221-1237.

Fletcher, R., Cornia, A., \& Nielsen, R. K. (2019). How polarized are online and offline news audiences? A comparative analysis of twelve countries. The International Journal of Press/Politics, 25(2), 69-195.

Fletcher, R., \& Nielsen, R. K. (2017). Are news audiences increasingly fragmented? A cross-national comparative analysis of cross-platform news audience fragmentation and duplication. Journal of Communication, 67(4), 476-498.

Flew, T., \& Waisbord, S. (2015). The ongoing significance of national media systems in the context of media globalization. Media, Culture \& Society, 37(4), 620-636.
Geiß, S., Magin, M., Stark, B., \& Jürgens, P. (2018). “Common Meeting Ground" in Gefahr? Selektionslogiken politischer Informationsquellen und ihr Einfluss auf die Fragmentierung individueller Themenhorizonte [Endangered common meeting ground? Selection logics of political information sources and their influence on the fragmentation of individual issue horizons]. M\&K Medien \& Kommunikationswissenschaft, 66(4), 502-525.

Gentzkow, M. A., \& Shapiro, J. M. (2010). What drives media slant? Evidence from US daily newspapers. Econometrica, 78(1), 35-71.

Gil de Zúñiga, H., \& Hinsley, A. (2013). The press versus the public: What is "good journalism?" Journalism Studies, 14(6), 926-942.

Goldman, S. K., \& Mutz, D. C. (2011). The friendly media phenomenon: A cross-national analysis of crosscutting exposure. Political Communication, 28(1), 42-66.

Greitemeyer, T., \& Schulz-Hardt, S. (2003). Preferenceconsistent evaluation of information in the hidden profile paradigm: Beyond group-level explanations for the dominance of shared information in group decisions. Journal of Personality and Social Psychology, 84(2), 322-339.

Gronke, P., \& Cook, T. E. (2007). Disdaining the media: The American public's changing attitudes toward the news. Political Communication, 24(3), 259-281.

Gunther, A. C., Edgerly, S., Akin, H., \& Broesch, J. A. (2012). Partisan evaluation of partisan information. Communication Research, 39(4), 439-457.

Hallin, D. C., \& Mancini, P. (2004). Comparing media systems. Cambridge: Cambridge University Press.

Hanitzsch, T., \& Berganza, R. (2012). Explaining journalists' trust in public institutions across 20 countries: Media freedom, corruption, and ownership matter most. Journal of Communication, 62(5), 794-814.

Harrell, F. E. (2019). rms: Regression Modeling Strategies [Computer software]. Retrieved from https://cran.rproject.org/web/packages/rms/index.html

Hartley, J. M. (2018). 'It's something posh people do': Digital distinction in young people's cross-media news engagement. Media and Communication, 6(2), 46-55.

Heider, D., McCombs, M., \& Poindexter, P. M. (2005). What the public expects of local news: Views on public and traditional journalism. Journalism \& Mass Communication Quarterly, 82(4), 952-967.

Holt, K., Figenschou, T. U., \& Frischlich, L. (2019). Key dimensions of alternative news media. Digital Journalism, 7(7), 860-869.

Hu, L.-t., \& Bentler, P. M. (1999). Cutoff criteria for fit indexes in covariance structure analysis: Conventional criteria versus new alternatives. Structural Equation Modeling: A Multidisciplinary Journal, 6(1), 1-55.

Huang, F. L. (2018). Using cluster bootstrapping to analyze nested data with a few clusters. Educational and Psychological Measurement, 78(2), 297-318. 
Iyengar, S., \& Hahn, K. S. (2009). Red media, blue media: Evidence of ideological selectivity in media use. Journal of Communication, 59(1), 19-39.

Jandura, O., \& Friedrich, K. (2014). The quality of media coverage. In C. Reinemann (Ed.), Handbooks of communication science: Political communication (Vol. 18, pp. 351-373). Berlin: De Gruyter Mouton.

Ladd, J. M. (2011). Why Americans hate the media and how it matters. Princeton, NJ: Princeton University Press.

Majó-Vázquez, S., Nielsen, R. K., \& González-Bailón, S. (2019). The backbone structure of audience networks: A new approach to comparing online news consumption across countries. Political Communication, 36(2), 227-240.

Mancini, P. (2013). Media fragmentation, party system, and democracy. The International Journal of Press/Politics, 18(1), 43-60.

Marquis, L., Schaub, H.-P., \& Gerber, M. (2011). The fairness of media coverage in question: An analysis of referendum campaigns on welfare state issues in Switzerland. Swiss Political Science Review, 17(2), 128-163.

Maurer, T. (2017). Quality. In P. Rössler, C. A. Hoffner, \& L. van Zoonen (Eds.), The Wiley Blackwell-ICA international encyclopedias of communication: The international encyclopedia of media effects (Vol. 30, pp. 1-8). Chichester: John Wiley \& Sons, Inc.

McDowell, W. S. (2011). The brand management crisis facing the business of journalism. International Journal on Media Management, 13(1), 37-51.

McQuail, D. (1992). Media performance: Mass communication and the public interest. London: SAGE Publications.

Mocek, S. (2019). A map of political discourse regarding Polish public service media. In E. Połońska \& C. Beckett (Eds.), Public service broadcasting and media systems in troubled European democracies (pp. 195-226). Cham: Springer International Publishing.

Mukerjee, S., Majó-Vázquez, S., \& González-Bailón, S. (2018). Networks of audience overlap in the consumption of digital news. Journal of Communication, 68(1), 26-50.

Napoli, P. M. (2011). Exposure diversity reconsidered. Journal of Information Policy, 1, 246-259.

Nechushtai, E. (2018). From liberal to polarized liberal? Contemporary US news in Hallin and Mancini's typology of news systems. The International Journal of Press/Politics, 23(2), 183-201.

Neuberger, C. (2014). The journalistic quality of internet formats and services. Digital Journalism, 2(3), 419-433.

Neuman, W. R., Park, Y. J., \& Panek, E. (2012). Tracking the flow of information into the home: An empirical assessment of the digital revolution in the United States. International Journal of Communication, 6, 1022-1041.

Newman, N., Fletcher, R., Kalogeropoulos, A., \& Nielsen,
R. K. (2019). Reuters Institute digital news report 2019. Oxford: Reuters Institute for the Study of Journalism.

Nord, L. (2016). Nordic media systems 1850-1950: Myths, mixtures and metamorphoses. In J. Harvard \& P. Stadius (Eds.), Nordic experience: Communicating the north: Media structures and images in the making of the Nordic region (pp. 25-46). London: Routledge.

Peters, C., \& Schrøder, C. K. (2018). Beyond the here and now of news audiences: A process-based framework for investigating news repertoires. Journal of Communication, 68(6), 1079-1103.

Peters, C., \& Witschge, T. (2015). From grand narratives of democracy to small expectations of participation. Journalism Practice, 9(1), 19-34.

Prior, M. (2007). Post-broadcast democracy: How media choice increases inequality in political involvement and polarizes elections. New York, NY: Cambridge University Press.

Rössler, P. (2007). Media content diversity: Conceptual issues and future directions for communication research. Annals of the International Communication Association, 31(1), 464-520.

Schudson, M. (2001). The objectivity norm in American journalism. Journalism: Theory, Practice \& Criticism, 2(2), 149-170.

Scott, B. (2005). A contemporary history of digital journalism. Television \& New Media, 6(1), 89-126.

Steenkamp, J.-B. E. M., \& Baumgartner, H. (1998). Assessing measurement invariance in cross-national consumer research. Journal of Consumer Research, 25(1), 78-107.

Stroud, N. J. (2011). Niche news: The politics of news choice. Oxford: Oxford University Press.

Tong, J. (2018). Journalistic legitimacy revisited: Collapse or revival in the digital age? Digital Journalism, 6(2), 256-273.

Towner, T., \& Lego Munoz, C. (2016). Boomers versus millennials: Online media influence on media performance and candidate evaluations. Social Sciences, 5(4). https://doi.org/10.3390/socsci5040056

Tsfati, Y. (2010). Online news exposure and trust in the mainstream media: Exploring possible associations. American Behavioral Scientist, 54(1), 22-42.

Tuchman, G. (1980). Making news: A study in the construction of reality. New York, NY: Free Press.

Umbricht, A., \& Esser, F. (2016). The push to popularize politics: Understanding the audience-friendly packaging of political news in six media systems since the 1960s. Journalism Studies, 17(1), 100-121.

Urban, J., \& Schweiger, W. (2014). News quality from the recipients' perspective: Investigating recipients' ability to judge the normative quality of news. Journalism Studies, 15(6), 821-840.

van Aelst, P., Strömbäck, J., Aalberg, T., Esser, F., de Vreese, C. H., Matthes, J., . . . Stanyer, J. (2017). Political communication in a high-choice media environ- 
ment: A challenge for democracy? Annals of the International Communication Association, 41(1), 3-27.

Van der Wurff, R., \& Schoenbach, K. (2014). Civic and citizen demands of news media and journalists: What does the audience expect from good journalism? Journalism \& Mass Communication Quarterly, 91(3), 433-451.

Webster, J. G. (2005). Beneath the veneer of fragmentation: Television audience polarization in a multichannel world. Journal of Communication, 55(2), 366-382.

Weeks, B. E., Ksiazek, T. B., \& Holbert, R. L. (2016). Partisan enclaves or shared media experiences? A net- work approach to understanding citizens' political news environments. Journal of Broadcasting \& Electronic Media, 60(2), 248-268.

Westerståhl, J. (1983). Objective news reporting. Communication Research, 10(3), 403-424.

Wolling, J. (2009). The effect of subjective quality assessment on media selection. In T. Hartmann (Ed.), Media choice (pp. 84-101). New York, NY: Routledge.

Yuan, E. J. (2008). Diversity of exposure in television viewing: Audience fragmentation and polarization in Guangzhou. Chinese Journal of Communication, 1(1), 91-108.

\section{About the Authors}

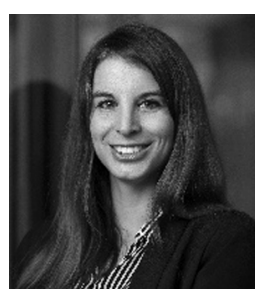

Desiree Steppat is Research and Teaching Associate at the Department of Communication and Media Research (IKMZ) at the University of Zurich. Her research interests include political communication, political journalism, and international and comparative media research, with a special focus on the role political information environments play in shaping individual news media use and perceptions.

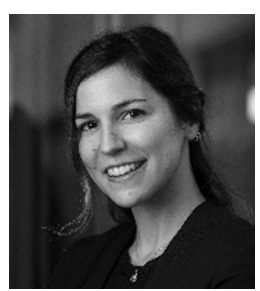

Laia Castro Herrero is Senior Research and Teaching Associate at the Department of Communication and Media Research (IKMZ) at the University of Zurich. She received her PhD in Social Sciences from the University of Fribourg in 2017. Her main research interests lie at the intersection of political communication, international and comparative media research and public opinion.

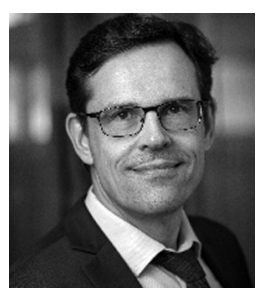

Frank Esser is Professor of International and Comparative Media Research at the University of Zurich. His research focuses on cross-national studies of news journalism and political communication. His books include the ICA Handbook of Comparative Communication Research (2012, with T. Hanitzsch), Mediatization of Politics (2014, with J. Strömbäck) and Comparing Political Journalism (with C. d. Vreese and D. Hopmann). 